\title{
Adults with Down Syndrome: Characterization of a Portuguese Sample
}

\author{
Adultos com Síndrome de Down: Caracterização de Uma Amostra Portuguesa
}

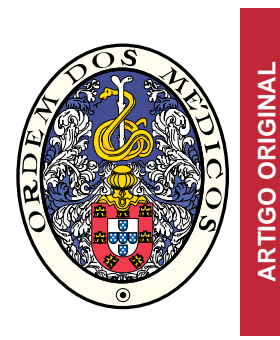

\author{
Paula BREIA ${ }^{1}$, Rosário MENDES ${ }^{1}$, Ana SILVESTRE ${ }^{1}$, Maria João GONÇALVES ${ }^{2}$, Maria João FIGUEIRA ${ }^{2}$, Regina \\ $\mathrm{BISPO}^{3}$ \\ Acta Med Port 2014 May-Jun;27(3):357-363
}

\section{ABSTRACT}

Introduction: Down syndrome or Trisomy 21 affects physical, behavioral and cognitive development. Ageing people with Down syndrome may suffer from several comorbidities that interfere with their daily life.

Objective: To analyze in a sample of adults with Down syndrome the presence of common medical diseases, regular use of medication, possible cognitive impairment and oral communication skills.

Material and Methods: The socio-demographic and clinical data of 209 Portuguese adults (20-58 years) with Down syndrome were collected. Twenty-six subjects were assessed with the WAIS-III. Data was statistically analyzed - SPSS (v.19).

Results: Almost half $(47.36 \%)$ of the sample suffers from comorbidities, with cardiac, psychiatric, epilepsy and hypothyroidism ranked as the most prevalent diseases. Seventy-two patients (34.45\%) take medication that acts on the central nervous system. The WAIS-III results revealed IQ scores between $45-61$ (mean $=49.65, \mathrm{SD}=4.93$ ) and 141 individuals $(67.5 \%)$ who can express themselves through basic oral language.

Discussion: In line with other studies, these individuals are vulnerable to various comorbidities. Most have basic oral language, but the $I Q$ values are in the 'extremely low' range, with better performance on verbal tasks.

Conclusion: The cognitive constraints and communication difficulties in the population with Down syndrome may difficult the early clinical recognition of comorbidities associated with ageing. The identification of new semiology, with caregiver support, is essential to ensure that appropriate care is provided to this population.

Keywords: Adult; Down Syndrome; Comorbidity; Portugal.

\section{RESUMO}

Introdução: A síndrome de Down ou Trissomia 21 afeta o desenvolvimento físico, comportamental e cognitivo. No decurso do enveIhecimento, a ocorrência de comorbilidades aumenta nesta população, sendo a sua deteção e tratamento precoces determinantes na sua qualidade de vida.

Objetivo: Analisar numa amostra de adultos com síndrome de Down a existência de doenças médicas comuns, uso regular de medicação, eventual disfunção cognitiva e capacidades de comunicação oral.

Material e Métodos: Foram coletados os dados sociodemográficos e clínicos de 209 adultos portugueses (20 - 58 anos), com síndrome de Down. Vinte e seis indivíduos foram avaliados com a WAIS-III. Os dados foram analisados estatisticamente - SPSS (v.19). Resultados: Quase metade da amostra $(47,36 \%)$ sofre de comorbilidades, sendo as doenças cardiacas, psiquiátricas, epilepsia e hipotiroidismo as mais prevalentes. Setenta e dois indivíduos (34,45\%) tomam medicação com ação no sistema nervoso central. Na WAIS-III, os valores de QI situam-se entre 45-61 ( $\mathrm{m}=49,65$, $\mathrm{dp}=4,93)$ existindo 141 indivíduos $(67,5 \%)$ capazes de se expressar através de linguagem oral básica.

Discussão: Os indivíduos desta amostra são vulneráveis a várias comorbilidades. A maioria tem linguagem oral básica, mas os valores de QI situam-se na faixa 'extremamente baixo', sendo melhor o desempenho em tarefas verbais.

Conclusão: As limitações cognitivas e dificuldades comunicacionais na população com síndrome de Down podem condicionar o reconhecimento clínico precoce de comorbilidades que lhe estão associadas no decurso do envelhecimento. A valorização semiológica, com apoio do cuidador, é essencial para garantir que os cuidados de saúde adequados são prestados a esta população.

Palavras-chave: Síndrome de Down; Comorbilidade; Portugal.

\section{INTRODUCTION}

Down syndrome (DS) is a chromosomal disorder caused by trisomy 21 . It is the most common genetic cause of intellectual disability (ID) and affects $0.6-1 / 1000$ newborns. ${ }^{1,2}$

DS is characterised by a well-recognized phenotype, affecting physical, behavioural and cognitive development. It is associated with a set of characteristic facial and musculoskeletal features, reduced birth weight, growth retardation, neurological complications and an increased risk for several medical conditions (e.g. congenital heart defects, hypothyroidism, gastrointestinal disease, childhood leukemia and early-onset dementia). ${ }^{3-5}$

DS phenotype includes significant developmental delay in cognitive functions. It affects attention, learning, memory and language skills. $4,6,7$

The degree of cognitive deficit of individuals with DS

\footnotetext{
1. Department of Neurology. Hospital Garcia de Orta. Almada. Portugal.

2. Department of Psychology. Cercizimbra. Sesimbra. Portugal.

3. Department of Statistics. Instituto Universitário de Ciências Psicológicas, Sociais e da Vida. Lisboa. Portugal.

Recebido: 07 de Outubro de 2013 - Aceite: 17 de Fevereiro de 2014 | Copyright $\odot$ Ordem dos Médicos 2014
} 
typically varies from mild to severe intellectual disability 8,9 with Intelligence Quotient (IQ) levels lower than $70 .^{9}$ In some patients, there is evidence of a decline in IQ levels during adulthood that may be due to ageing, gradual brain deterioration (memory, language and cognitive functioning), but also to a high prevalence of dementia in adults with DS. ${ }^{1,4}$ In one specific study it was found that women with DS had milder levels of ID, more developed speech and better daily life skills. ${ }^{10}$

Communication skills are also impaired in most adults with DS. When compared to individuals of the same chronological age or to other inherited disorders coursing with ID (e.g. Fragile $X$ syndrome), there is a predominance of language defects in DS patients..$^{11,12}$

Ageing people with DS may also suffer from a range of diseases, some of which are frequently associated with Alzheimer's disease, namely lung disease, epilepsy, visual and hearing impairments, depression, immobility, among others. ${ }^{13}$ The anticipated diagnosis and appropriate responses to treatable comorbid conditions may reduce their impact on the quality of life of people with $D S$ and $A D^{13,14}$

Adults with DS are also vulnerable to psychopathologic and psychiatric disorders, despite the lower prevalence of mental illness when comparing to other adults with ID. ${ }^{15,16}$ Nevertheless, suffering from DS results in an increased risk of developing psychological and neuropsychological conditions such as depression, anxiety and dementia. $4,6,10,16,17$

\section{MATERIAL AND METHODS}

The characteristics of adults with Down syndrome are poorly studied in the Portuguese population. Most of these individuals are not regularly seen by a physician and have no medical follow-up after childhood. Moreover, any maladaptive behaviour or cognitive decline are commonly interpreted by caregivers as being part of the disease phenotype.

This has prompted the present research study about the characteristics of the Portuguese adult population with DS. The aims of this study were: 1) To determine the existence of common medical disease, 2) To determine the regular use of medication, 3) To evaluate the presence of oral communication skills, 4) To analyse the degree of cognitive impairment of the sample through IQ values, 5) To identify gender differences in WAIS-III performance.

\section{Type of study}

This is an exploratory study to determine the sociodemographic and clinical characteristics of a sample of adults with DS who attend institutional facilities for people with ID in the Lisbon metropolitan area.

\section{Participants}

Two hundred and nine adults compose the present sample with DS collected from 15 institutional facilities for people with ID in Lisbon. One hundred and twenty five of these $(59.8 \%)$ are male and $84(40.2 \%)$ are female and aged between 20 and 58 years $(m=36.25$, $s d=8.35)$.
Of this initial sample, 26 individuals (approximately $10 \%$ of the total) present verbal oral language skills and could therefore be assessed using the Wechsler Adult Intelligence Scale (WAIS-III). The socio-demographic characteristics of these subjects are presented in Table 1.

\section{Instruments}

a. Socio-demographic and medical forms - The data collected from the institutions included information about gender, date of birth, presence of verbal oral language skills, comorbidities and current medication for each subject.

b. WAIS-III - The third edition of the Portuguese version of the Wechsler Adult Intelligence Scale ${ }^{18}$ was applied. This instrument allows the assessment of individuals' intellectual functioning. It is composed of 14 tests, divided into 7 verbal subscales and 7 performance subscales. The conversion of scores determines the values of Verbal IQ, Performance $I Q$, and Full Scale $I Q$, along with four factor indices (Verbal Comprehension, Working Memory, Perceptual Organization, and Processing Speed).

Table 1 - Socio-Demographic Characteristics of the Individuals Assessed with the WAIS-III

\begin{tabular}{|c|c|c|c|}
\hline Subject nr. & Gender & Age (yrs) & Institution nr. \\
\hline 1 & Male & 29 & 1 \\
\hline 2 & Female & 46 & 2 \\
\hline 3 & Male & 48 & 2 \\
\hline 4 & Female & 26 & 2 \\
\hline 5 & Female & 44 & 2 \\
\hline 6 & Female & 35 & 3 \\
\hline 7 & Female & 24 & 5 \\
\hline 8 & Female & 26 & 6 \\
\hline 9 & Male & 27 & 6 \\
\hline 10 & Male & 34 & 7 \\
\hline 11 & Male & 24 & 8 \\
\hline 12 & Male & 36 & 11 \\
\hline 13 & Male & 27 & 11 \\
\hline 14 & Female & 38 & 11 \\
\hline 15 & Male & 29 & 14 \\
\hline 16 & Female & 36 & 14 \\
\hline 17 & Male & 36 & 14 \\
\hline 18 & Female & 39 & 14 \\
\hline 19 & Male & 36 & 15 \\
\hline 20 & Female & 29 & 10 \\
\hline 21 & Male & 37 & 3 \\
\hline 22 & Male & 36 & 3 \\
\hline 23 & Male & 36 & 3 \\
\hline 24 & Male & 26 & 7 \\
\hline 25 & Female & 24 & 1 \\
\hline 26 & Male & 20 & 14 \\
\hline
\end{tabular}




\section{Procedure}

In order to accomplish the data collection, we held several meetings with the directors of institutions for people with ID and with the DS individuals' legal guardians or relatives. Information about the study's aims and procedures was provided, and then the invitation to participate in the study was made. After relatives' informed consent was obtained, the institutions provided the socio-demographic and medical information of the DS subjects. The first phase of the study involved the review of the medical records of 209 individuals of both sexes. A chromosomal test confirming trisomy 21 was available in each case. A separate informed consent was obtained later from legal guardians, allowing the IQ assessment with the Portuguese version of WAIS-III.

From the initial 209 records, 147 legal guardians denied this cognitive assessment, another two DS adults abandoned the institution they were attending, and were therefore not cognitively assessed; 30 individuals did not have the necessary verbal oral language skills to perform the test (i.e., the ability to produce speech from single spoken words to short sentences). In the end, only 26 DS participants were assessed to determine IQ level with the WAIS-III (Fig. 1).

\section{Statistical analysis}

We analysed the data using the Statistical Package for the Social Sciences (SPSS, version 19). Both descriptive and inferential statistical analyses were used. Normality tests were run using Shapiro-Wilk tests for the WAISIII IQ values, factor indices and subscales regarding the participants' gender. The results revealed that in most cases the distribution of scores was significantly different from a normal distribution $(p<0.05)$. For this reason, we used Mann-Whitney tests (for the significance level of 0.05 ) to identify possible differences between men and women's performance in WAIS-III.

\section{RESULTS}

\section{Comorbidities and regular use of medication}

From the 209 individuals in our sample, 99 (47.36\%) suffer from comorbidities. Of these 99 individuals, 63

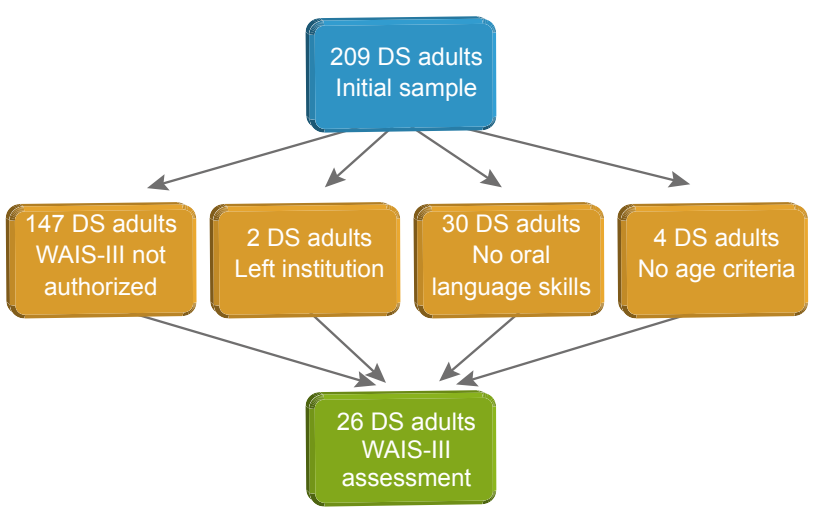

Figure 1 - General performance of the DS subjects on the WAIS-III subscales
$(63.6 \%)$ are male and $36(36.4 \%)$ are female. They have a mean age of 37 years $(s d=8.38)$.

Table 2 indicates that the most frequent co-morbidity in this group of individuals is cardiac disease $(21.5 \%)$, followed by psychiatric disease (14.1\%), epilepsy (8.5\%), hypothyroidism $(7.3 \%)$ and venous insufficiency $(6.2 \%)$. From the 38 individuals who suffer from cardiac disease, 3 suffer from congenital heart disease and have been previously submitted to surgery. The others have cardiac insufficiency. Twenty five participants suffer from psychiatric disease: 18 present psychotic behaviour, 16 have either depressive or anxiety symptoms and 2 have sleeping difficulties. It is not uncommon that psychiatric problems overlap which, in fact, happens in 11 cases.

From our sample of DS individuals, 72 (34.45\%) are under some kind of medication. They have a mean age of

Table 2 - Presence of Comorbidities

\begin{tabular}{|c|c|c|}
\hline Co-morbidity & Frequency & $\%$ \\
\hline Cardiac disease & 38 & 21.5 \\
\hline Congenital heart disease & 3 & 7.9 \\
\hline Cardiac insufficiency & 35 & 92.1 \\
\hline Psychiatric disease & 25 & 14.1 \\
\hline Psychotic disorder & 18 & 72.0 \\
\hline Depressive symptoms & 8 & 32.0 \\
\hline Anxiety & 8 & 32.0 \\
\hline Sleeping problems & 2 & 8.0 \\
\hline Epilepsy & 15 & 8.5 \\
\hline Hypothyroidism & 13 & 7.3 \\
\hline Venous insufficiency & 11 & 6.2 \\
\hline Hyperuricemia & 9 & 5.1 \\
\hline Digestive disease & 8 & 4.5 \\
\hline Other treatable causes of dementia & 8 & 4.5 \\
\hline Hypertension & 7 & 4.0 \\
\hline Diabetes & 6 & 3.4 \\
\hline Hypercholesterolemia & 6 & 3.4 \\
\hline Liver disease & 6 & 3.4 \\
\hline Hematologic disease & 5 & 2.8 \\
\hline Obesity & 4 & 2.3 \\
\hline Allergy & 3 & 1.7 \\
\hline Kidney disease & 3 & 1.7 \\
\hline Osteoporosis & 3 & 1.7 \\
\hline Vascular disease & 3 & 1.7 \\
\hline Dermatologic disease & 2 & 1.1 \\
\hline Hyperthyroidism & 1 & 0.6 \\
\hline Others & 1 & 0.6 \\
\hline Total co-morbidities & 177 & 100.0 \\
\hline
\end{tabular}


Table 3 - Mean, Standard Deviation (sd) and Range Values of IQ Level, Verbal Comprehension Index and Perceptual Organization Index

\begin{tabular}{lccc}
\hline IQs and Indices & $m$ & sd & Range \\
\hline Full Scale IQ & 49.65 & 4.94 & $45-61$ \\
Verbal IQ & 52.27 & 5.65 & $45-64$ \\
Performance IQ & 50.77 & 5.06 & $45-62$ \\
& & & \\
Verbal Comprehension & 57.27 & 7.83 & $50-77$ \\
& & & \\
Perceptual Organization & 53.85 & 4.93 & $50-64$ \\
\hline
\end{tabular}

38.5 years $(s d=8.58)$. They take 2 medicines $(s d=1.44$; range $=1-8$ pills), from 1 to 4 different types of drugs.

The majority of the drugs taken by our DS adults (28.8\%) are prescribed to control psychiatric disease (antipsychotics, antidepressants, benzodiazepines and sleep inducers), followed by antiepileptic drugs $(14.4 \%)$, thyroid hormone replacement drugs (8.9\%) and venotropics (6.8\%).

\section{Verbal oral language skills}

From the 209 individuals, 141 (67.5\%) have skills in the domain of verbal oral language. Half of these people $(51.8 \%)$ are males. Fifty-six individuals $(26.8 \%)$ of the total sample are unable to express themselves using verbal oral language.

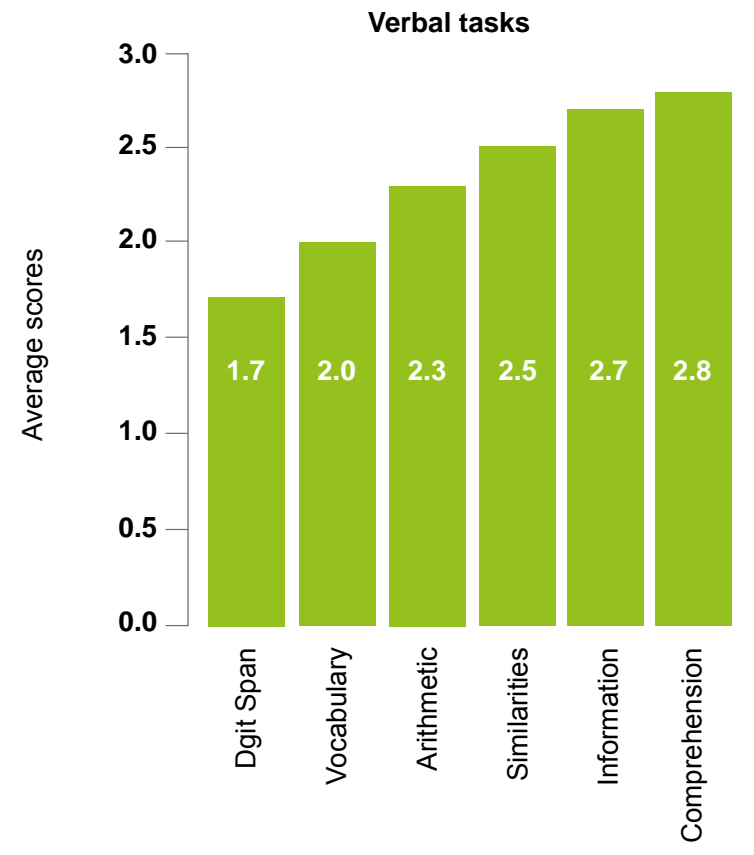

\section{Intelligence Quotient (IQ) and WAIS-III performance}

The results of WAIS-III for the 26 DS subjects that we assessed are shown in Table 3. Scores range between 45 and $61(m=49.65, s d=4.93)$ in the Full Scale IQ. Verbal $\mathrm{IQ}$ values were between 45 and 64 points $(m=52.27$, $s d=5.65)$, and Performance $I Q$ levels ranged from 45 to 62 points $(m=50.77, s d=5.06)$. Considering the Factor Indices, the participants achieved values of Verbal Comprehension between 50 and 77 points $(m=57.27$, sd $=$ 7.83), while Perceptual Organization levels ranged from 50 to 64 points $(m=53.85$, $s d=4.93)$.

Males had higher mean values of Full Scale IQ ( $m=$ $50.47, s d=4.84)$ than females $(m=48.55$, $s d=5.09)$, as well as higher Verbal IQ levels $(m=52.93$, $s d=5.89$ and $m=51.36, s d=5.46$, respectively), and Performance $I Q$ levels $(m=51.47, s d=5.18$ and $m=49.82$, $s d=4.98$, respectively). However, these differences are not statistically significant.

Subscale analysis (Fig. 2) showed an overall better performance on Comprehension ( $m=2.8, s d=1.6$ ), Information ( $m=2.7, s d=2.0$ ), and Picture arrangement ( $m=2.7, s d=2.3$ ) tasks. The lowest scores were found on Picture Completion ( $m=1.5, s d=0.9$ ), Digit symbol - code ( $m=1.6, s d=1.0)$, and Digit Span ( $m=1.7, s d=1.2)$.

Males ( $m=2.27, s d=1.03$ ) had a significantly better performance $(u=47, p<.05)$ on the Vocabulary task than females $(m=1.55, s d=0.69)$, with a medium to large effect size of 0.4 .

\section{DISCUSSION}

Advances in medical treatment and improved living conditions have resulted in longer life expectancy rates of

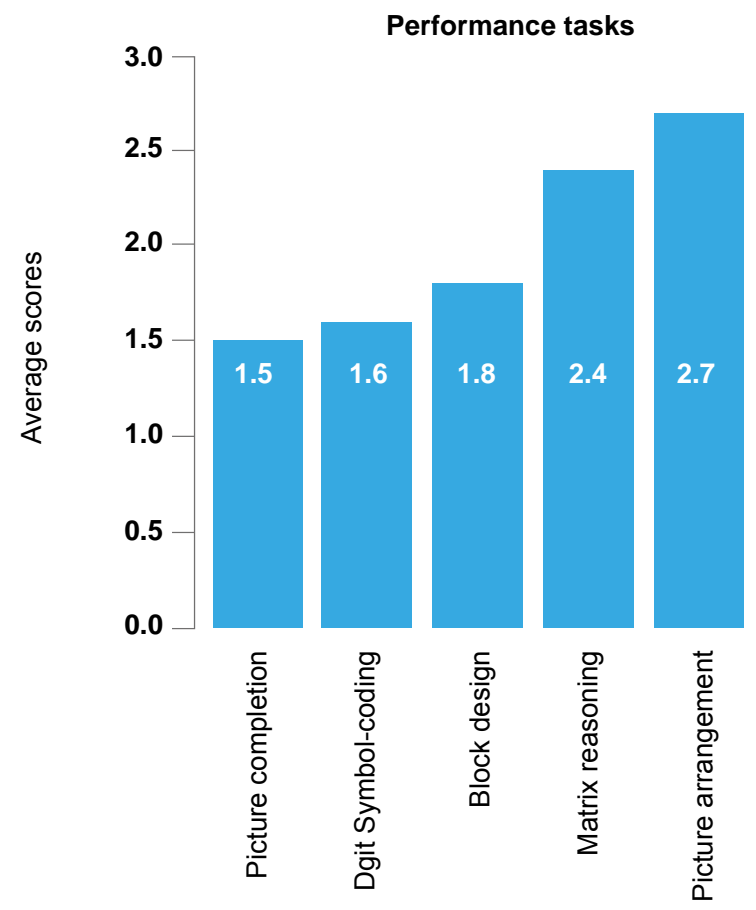

Figure 2 - The recruitment process of the patients assessed with the WAIS-III 
individuals with Down syndrome.

Age is a factor of change in individuals' health, skills and behaviour. Learning and acquisition of skills in youth may be followed by a gradual loss of capacities in adulthood and later life. ${ }^{10}$ In our sample, $67.5 \%$ of the individuals displayed some kind of basic verbal oral language skills, i.e., the capacity to produce speech, from single spoken words to short sentences. Their performance in WAIS-III revealed IQ scores in the 'extremely low' range according to Wechsler's classification. These results were not unexpected, given the subjects' intellectual disability and they are in keeping with previous studies concerning individuals with Down syndrome. ${ }^{9}$ Nevertheless, it has to be remembered that we only managed to recruit 26 patients out of 209 , which can most probably bias the results. Subjects performed relatively well on Comprehension, Information and Picture arrangement tasks, but poorly on Picture Completion, Digit symbol - code and Digit Span tests. This profile of performance indicates weaknesses in specific skills: ${ }^{19}$ attention and concentration, information codification for processing, work with numbers, sequencing, short-term memory (auditory or visual), symbolic content and visual memory. It does, nevertheless, point to relative strengths, namely comprehension of long questions, common sense, social understanding, simple cultural knowledge, and basic reasoning. Such a pattern of memory deficits in DS individuals has been widely documented, especially those related to working memory and short-term verbal memory, 3,6,8,20 as well as attention problems. However, in our sample Verbal IQ was higher than Performance IQ; also, Verbal Comprehension Indexes were on average higher than Perceptual Organization Indexes. It is a fact that DS population has a heterogeneous cognitive profile, but they generally perform better on non-verbal skills than on verbal ones. These apparently unexpected results may be explained by the fact that all participants needed to have some oral language skills to be included in the study, possibly influencing the results. But this was a necessary requirement in order to accomplish the assessment. Concerning language skills of DS adults, several published studies and reviews indicate that expressive language is more compromised than comprehension in these subjects. ${ }^{3,5,6,8,12}$ Other authors suggest that the severity of language impairment is variable and that the language components (phonology, semantics, syntax, pragmatics) are affected to different degrees. ${ }^{8}$ This was also observed in this sample. Despite poor speech intelligibility and weaknesses of speech, vocabulary, and syntax skills, ${ }^{5,21}$ the verbal production of DS individuals is minimally appropriate to the social context and to fulfil conversational functions, ${ }^{22}$ such as those necessary to the context of evaluation. However, even if they use communicational alternatives to overcome their limitations, such as imitation and gesture, ${ }^{5,21,23}$ they often fail to convey information in effective and understandable ways. $^{23}$ Nevertheless, 'it seems possible to characterise the language of most adults with DS as formally restricted (particularly morphosyntactically), often deficient as to articulation and phonological processes, but semantically, pragmatically and communicatively appropriate to minimal cognitive and social demands. ${ }^{22}$

Gender differences were also found in the present study. Male subjects performed better than women in the Vocabulary task. These results are opposite to those of a Finnish study where women of the sample had milder levels of ID, more often developed speech and had better adaptation skills. ${ }^{10}$

From a medical perspective, individuals with DS generally have poorer health status than individuals with other ID. ${ }^{24}$ They are vulnerable to several medical disorders that may be treatable but if undiagnosed, will worsen the burden of these individuals, of their families and carers. ${ }^{14}$ In our sample, almost half of the subjects $(47.36 \%)$ suffer from at least one comorbidity. The most prevalent medical conditions are cardiac disease (21.6\%), followed by psychiatric disease (14.2\%), epilepsy $(8.5 \%)$, hypothyroidism (7.4\%) and venous insufficiency $(6.3 \%)$.

Some authors point to the fact that Down syndrome, as a multi-organ disorder, interferes with the functioning and the structure of the heart and vascular systems, ${ }^{25}$ of which cardiac impairment, especially congenital heart disease is one of the most frequent co-morbidities. ${ }^{25,26}$ The underlying genetic disease seems to set a pattern of congenital heart defects, ${ }^{25}$ which are responsible for a large percentage of the main causes of death in adults with DS and heart failure..$^{2,27}$

As expected, hypothyroidism was a frequent comorbidity in our sample. Several previous studies have reported thyroid dysfunction in DS individuals, especially hypothyroidism. ${ }^{14,17,28}$ Other studies have described additional medical issues in DS adults, including skin and hair diseases, early-onset menopause, visual and hearing impairments, pulmonary disease, obstructive sleep apnoea, musculoskeletal disease, type 1 diabetes mellitus, overweight and obesity, gastroesophageal reflux disease, celiac disease and an age-related increased risk for dementia. 14,17,25-27,29,30 The likelihood of epilepsy and seizures increases with age, especially if there is comorbid dementia, but is also related to the age of onset of the disease. ${ }^{29}$ In some studies, older adults with DS were found to have a higher incidence of respiratory disease and congenital anomalies, ${ }^{29}$ dementia, hypothyroidism, skin problems,${ }^{17}$ cardiac disease, neurologic disease as well as shorter height and stature. ${ }^{24}$ Osteoporosis was found more frequently in a younger sample (<50 years old). ${ }^{17}$ Comparing to these studies, we found lower rates of osteoporosis $(1.7 \%)$, obesity $(2.3 \%)$ and skin conditions $(1.1 \%)$. DS adults seem to be at lower risk for malignant solid tumours ${ }^{29}$ than the general population. In fact, none of our DS patients had been diagnosed with cancer malignancy.

Concerning medication use, one study ${ }^{17}$ revealed that the number of drugs used by adults with DS ranged from 0 to 16 per person. This is not a surprising fact given the DS' adults vulnerability to several medical conditions and the consequent need to take medication. The most frequently 
prescribed drugs to the patients of that study were thyroid hormones, calcium, anti-anxiety and antidepressant medications, multivitamins, vitamin $\mathrm{E}$ supplements, and drugs for gastroesophageal reflux disease and for respiratory disorders. In line with these findings, less than half of the subjects of our sample (34.45\%) were on medication for the most common comorbidities. The number of medications used range from 1 to 8 medications per adult, including 1 to 4 different types of drugs. The most common drugs were those prescribed for psychiatric disease (antipsychotics, antidepressants, benzodiazepines and sleep inducers), antiepileptic drugs, thyroid supplementation and venotropic drugs. However, although we observed that 38 adults suffered from cardiac disease, only 4 needed medication. In fact, 3 individuals suffered from congenital heart disease - corrected while they were infants - and the other 35 had non severe cardiac insufficiency. Cardiac disease is the most frequent comorbidity, but it is not too severe in this sample.

We also observed that psychiatric diseases affected $14.1 \%$ of the present sample, the most prevalent being psychosis, depression, anxiety and insomnia. Several subjects were taking more than one type of psychiatric medication. These drugs seem to have an effective impact on the subjects' behaviour.

It is well known that adults with DS are particularly vulnerable to psychopathology and psychiatric disorders, despite the low prevalence of mental illness in this population. ${ }^{15,16}$ Depression, mania, schizophrenia, behavioural disease, personality disorders and neurotic disorders are the most frequent disorders, but depression has a major significance during adulthood.,16,31 Due to language impairment, depression and psychiatric symptoms in people with DS are rarely verbalised and are frequently perceived through behaviours like crying, depressed appearance, mood liability and vegetative symptoms (disinterest, withdrawal and mutism, psychomotor retardation, appetite loss, weight loss and insomnia). ${ }^{10}$ Some of the cognitive deficits such as language impairment or difficulty in following instructions may cause behavioural problems, aggression and frustration. ${ }^{32}$ On the other hand, the early-onset dementia of the Alzheimer type and cognitive decline can interfere with the adequate identification of depressive symptoms; moreover, medical issues such as hypothyroidism can mimic or exacerbate symptoms of depression. ${ }^{15}$

Several studies indicate that adults with DS are at a particularly high risk for early-onset dementia and have high rates of dementia of Alzheimer's type. . $15,33,34^{\text {As previously }}$ stated, this disorder is associated with substantial comorbidity and mortality, and frequently overshadows the diagnosis of the other disorders of aging. ${ }^{34}$ Differential diagnosis requires the exclusion of other causes of cognitive decline such as medical conditions, medication effects, psychiatric disorders, changes in environment/bereavement and abuse $e^{9,14,35}$ It is also essential to correctly differentiate age-related cognitive decline from early dementia, ${ }^{9}$ since cognitive abilities in most people with DS are below the average level even before they develop dementia, ${ }^{32}$ and the domains of communication and socialization are markedly affected by age. ${ }^{36}$ Thus, a baseline assessment of functioning must be established for future reference and comparison. ${ }^{9}$

This study presents several limitations. The overall results are limited by the small sample of just 26 subjects assessed with the WAIS-III. In fact, considering the initial number of 209 records, there was a large amount of dropouts and exclusions. On one hand, legal guardians have not authorized the IQ assessment, which immediately reduced the number of available participants. On the other hand, it was necessary to include only individuals with at least basic linguistic skills in order to proceed with the study. Thus, it becomes evident that this is still a difficult population to evaluate.

Nevertheless, the presence of language skills in the majority of the individuals of the final sample will allow further neuropsychological assessment, after the exclusion of relevant comorbidities which might compromise the possible diagnosis of cognitive decline and dementia. Following each subject's medical and neuropsychological status at regular intervals will enable us to detect early signs of dementia and prevent adverse effects of existent or future comorbidities in this population.

\section{CONCLUSIONS}

This study makes an approach to the main comorbidities and cognitive skills of the adult population with Down syndrome in a Portuguese sample. Given the incidence and prevalence of medical problems in adults with Down syndrome, but also their frequent difficulty to properly communicate the pain or discomfort they may feel, it is not surprising that missed or misdiagnosis of physical and neuropsychological illness may occur. It is of the utmost importance to ensure that appropriate healthcare is provided to these patients in order to prevent and reduce the adverse effects of many of those conditions. This requires consistent solid knowledge about health issues associated with DS, factors that may overshadow relevant symptoms, cognitive limitations and communicational difficulties, as well as the risk for early dementia. In clinical practice, regular age and gender appropriate screening by primary care physicians and specialists is needed in order to identify DS specific comorbidities, aiming at a personalized medicine and the search for the best practices. ${ }^{26,27,37}$ This implies that health care professionals are prepared to diagnose, treat and manage these medical conditions. ${ }^{37}$ Dealing with people with ID and their families in an effective manner requires both knowledge and empathy. On the other hand, "individuals themselves and their caregivers need to be educated about the health difficulties and disorders that need to be observed" 27 facilitating the screening and diagnosis process and contributing to their own quality of life. 


\section{ACKNOWLEDGEMENTS}

The authors would like to thank the families, the participants with Down syndrome and the institutions who gave their contribution to this study.

The authors further thank Miguel Viana Baptista for his support throughout the study and Cristina Martins da Costa for her support and the revision of the manuscript.

\section{REFERENCES}

1. Pennington BF, Moon J, Edgin J, Stedron J, Nadel L. The neuropsychology of Down syndrome: evidence for hippocampal dysfunction. Child Dev. 2003;74:75-93

2. Bittles $A H$, Bower $C$, Hussain R, Glasson EJ. The four ages of Down syndrome. Eur J Public Health. 2007;17:221-5.

3. Silverman W. Down syndrome: cognitive phenotype. Ment Retard Dev Disabil Res Rev. 2007;13:228-36.

4. Lott IT, Dierssen M. Cognitive deficits and associated neurological complications in individuals with Down's syndrome. Lancet Neurol. 2010;9:623-33.

5. Roberts JE, Price J, Malkin C. Language and communication development in Down syndrome. Ment Retard Dev Disabil Res Rev. 2007; 13:26-35.

6. Chapman RS, Hesketh LJ. Behavioral phenotype of individuals with Down syndrome. Ment Retard Dev Disabil Res Rev. 2000;6:84-95.

7. Nelson LD, Orme D, Osann K, Lott IT. Neurological changes and emotional functioning in adults with Down Syndrome. J Intellect Disabil Res. 2001;45:450-6.

8. Laws $\mathrm{G}$. Contributions of phonological memory, language comprehension and hearing to the expressive language of adolescents and young adults with Down syndrome. J Child Psychol Psychiatr. 2004;45:1085-95.

9. Stanton LR, Coetzee RH. Down's syndrome and dementia. Adv Psychiatr Treat. 2004;10:50-8

10. Määttä $T$, Tervo-Määttä $T$, Taanila $A$, Kaski M, livanainen M. Mental health, behaviour and intellectual abilities of people with Down syndrome. Down Syndr Res Pract. 2006;11:37-43

11. Finestack $L H$, Palmer $M$, Abbeduto $L$. Macrostructural narrative language of adolescents and young adults with Down syndrome or Fragile X syndrome. Am J Speech Lang Pathol. 2012;21:29-46.

12. Finestack $\mathrm{LH}$, Abbeduto $\mathrm{L}$. Expressive language profiles of verbally expressive adolescents and young adults with Down syndrome or Fragile X syndrome. J Speech Lang Hear Res. 2010;53:1334-48.

13. McCarron M, Gill M, McCallion P, Begley C. Health co-morbidities in ageing persons with Down syndrome and Alzheimer's dementia. J Intellect Disabil Res. 2005;49:560-6.

14. Henderson A, Lynch SA, Wilkinson S, Hunter M. Adults with Down's syndrome: the prevalence of complications and health care in the community. Brit J Gen Pract. 2007;57:50-5.

15. Visootsak J, Sherman S. Neuropsychiatric and behavioral aspects of Trisomy 21. Curr Psychiatry Rep. 2007;9:135-40.

16. Mantry D, Cooper SA, Smiley E, Morrison J, Allan L, Williamson A, et al. The prevalence and incidence of mental ill-health in adults with Down syndrome. J Intellect Disabil Res. 2008;52:141-55.

17. Kerins G, Petrovic K, Bruder MB, Gruman C. Medical conditions and medication use in adults with Down syndrome: a descriptive analysis. Down Syndr Res Pract. 2008;12:141-7.

18. Wechsler D. WAIS-III - Escala de Inteligência de Wechsler para Adultos. $3^{\mathrm{a}}$ ed. Lisboa: CEGOC; 2008.

19. Kaufman AS, Lichtenberger EO. Claves para la evaluación con el WAIS-

\section{CONFLICT OF INTEREST}

The authors have no conflicts of interest to report.

\section{FUNDING SOURCES}

This study received funding from the Portuguese Foundation for Science and Technology (PTDC/PSIPCO/104296/2008).

III. Madrid: TEA Ediciones; 2004

20. Vicari S, Marotta L, Carlesimo GA. Verbal short-term memory in Down's syndrome: an articulatory loop deficit? J Intellect Disabil Res. 2004;48:80-92.

21. Martin GE, Klusek J, Estigarribia B, Roberts JE. Language characteristics of individuals with Down syndrome. Top Lang Disord. 2009;29:112-32.

22. Rondal JA, Comblain A. Language in adults with Down syndrome. Downs Syndr Res Pract. 1996;4:3-14.

23. Abbeduto L, Warren SF, Conners FA. Language development in Down syndrome: from the prelinguistic period to the acquisition of literacy. Ment Retard Dev Disabil Res Rev. 2007;13:247-61.

24. Carmeli E, Kessel S, Bar-Chad S, Merrick J. A comparison between older persons with Down syndrome and a control group: clinical characteristics, functional status and sensorimotor function. Downs Syndr Res Pract. 2004;9:17-24.

25. Vis JC, Duffels MG, Winter MM, Weijerman ME, Cobben JM, Huisman SA, et al. Down syndrome: a cardiovascular perspective. J Intellect Disabil Res. 2009;53:419-25

26. McCabe LL, McCabe ER. Personalized medicine for individuals with Down syndrome. Mol Genet Metab. 2011;104:7-9.

27. Prasher V. Screening of medical problems in adults with Down syndrome. Downs Syndr Res Pract. 1994;2:59-66.

28. Prasher V. Prevalence of thyroid dysfunction and autoimmunity in adults with Down syndrome. Downs Syndr Res Pract. 1994;2:67-70.

29. Esbensen AJ. Health conditions associated with aging and end of life of adults with Down syndrome. Int Rev Res Ment Retard. 2010;39:107-26.

30. Tenenbaum A, Chavkin M, Wexler ID, Korem M, Merrick J. Morbidity and hospitalizations of adults with Down syndrome. Res Dev Disabil. 2012;33:435-41.

31. Dykens EM. Psychiatric and behavioral disorders in persons with Down syndrome. Ment Retard Dev Disabil Res Rev. 2007;13:272-8.

32. Deb S, Hare M, Prior L. Symptoms of dementia among adults with Down's syndrome: a qualitative study. J Intellect Disabil Res. 2007;51:726-39.

33. Esbensen AJ, Seltzer MM, Krauss MW. Stability and change in health, functional abilities, and behavior problems among adults with and without Down syndrome. Am J Ment Retard. 2008;113:263-77.

34. Torr J, Strydom A, Patti P, Jokinen N. Aging in Down syndrome: morbidity and mortality. J Policy Pract Intellect Disabil. 2010;7:70-81.

35. Margallo-Lana ML, Moore PB, Kay DW, Perry RH, Reid BE, Berney TP, et al. Fifteen-year follow-up of 92 hospitalized adults with Down's syndrome: incidence of cognitive decline, its relationship to age and neuropathology. J Intellect Disabil Res. 2007;51:463-77.

36. Di Nuovo S, Buono S. Behavioral phenotypes of genetic syndromes with intellectual disability: comparison of adaptive profiles. Psychiatr Res 2011;189:440-5.

37. Jensen KM, Taylor LC, Davis MM. Primary care for adults with Down syndrome: adherence to preventive healthcare recommendations. J Intellect Disabil Res. 2013;57:409-21. 


\section{Adults with Down Syndrome: Characterization of a Portuguese Sample Acta Med Port 2014:27:357-363}

Publicado pela Acta Médica Portuguesa, a Revista Científica da Ordem dos Médicos

Av. Almirante Gago Coutinho, 151

1749-084 Lisboa, Portugal.

Tel: +351 218428215

E-mail: submissao@actamedicaportuguesa.com

www.actamedicaportuguesa.com

ISSN:0870-399X | e-ISSN: 1646-0758

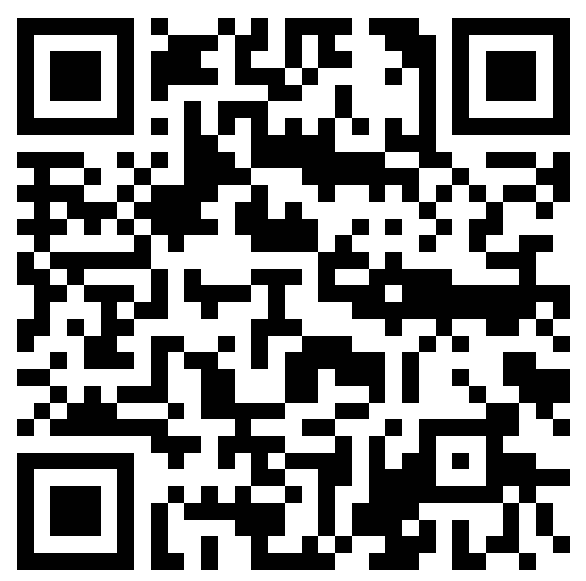

